\title{
Impact of delay to surgery on survival in stage I-III colon cancer
}

\author{
Fabian Grass ${ }^{\text {a, b, } 1}$, Kevin T. Behm ${ }^{\text {a, *, }}{ }^{\text {, Emilie Duchalais }}{ }^{\text {a }}$, Jacopo Crippa ${ }^{\text {a }}$ \\ Grant M. Spears ${ }^{\text {c }}$, William S. Harmsen ${ }^{\text {c}}$, Martin Hübner ${ }^{b}$, Kellie L. Mathis ${ }^{a}$, \\ Scott R. Kelley ${ }^{\mathrm{a}}$, John H. Pemberton ${ }^{\mathrm{a}}$, Eric J. Dozois ${ }^{\mathrm{a}}$, David W. Larson ${ }^{\text {a }}$ \\ a Division of Colon and Rectal Surgery, Mayo Clinic, 200 First Street SW, Rochester, MN, 55905, USA \\ ${ }^{\mathrm{b}}$ Department of Visceral Surgery, Lausanne University Hospital, Bugnon 46, 1011, Lausanne, Switzerland \\ ${ }^{c}$ Department of Biostatistics, Mayo Clinic, Rochester, MN, 55905, USA
}

\section{A R T I C L E I N F O}

\section{Article history:}

Received 7 July 2019

Received in revised form

11 October 2019

Accepted 27 November 2019

Available online 28 November 2019

\section{Keywords:}

Colon cancer

Survival

Treatment delay

\begin{abstract}
A B S T R A C T
Purpose: To assess the impact of delay from diagnosis to curative surgery on survival in patients with non-metastatic colon cancer.

Methods: National Cancer database (NCDB) analysis (2004-2013) including all consecutive patients diagnosed with stage I-III colon cancer and treated with primary elective curative surgery. Short and long delays were defined as lower and upper quartiles of time from diagnosis to treatment, respectively. Age-, sex-, race-, tumor stage and location-, adjuvant treatment-, comorbidity- and socioeconomic factorsadjusted overall survival (OS) was compared between the two groups (short vs. long delay). A multivariable Cox regression model was used to identify the independent impact of each factor on OS.

Results: Time to treatment was $<16$ days in the short delay group (31,171 patients) and $\geq 37$ days in the long delay group (29,617 patients). OS was 75.4 vs. $71.9 \%$ at 5 years and 56.6 vs. $49.7 \%$ at 10 years in short and long delay groups, respectively (both $\mathrm{p}<0.0001$ ). Besides demographic (comorbidities, advanced age) and pathological factors (transverse and right-vs. left-sided location, advanced tumor stage, poor differentiation, positive microscopic margins), treatment delay had a significant impact on OS (HR 1.06, 95\% CI 1.05-1.07 per 14 day-delay) upon multivariable analysis. The adjusted hazard ratio for death increased continuously with delay times of longer than 30 days, to become significant after a delay of 40 days.

Conclusion: This analysis using a national cancer database revealed a significant impact on OS when surgeries for resectable colon cancer were delayed beyond 40 days from time of diagnosis.
\end{abstract}

(c) 2019 Elsevier Ltd, BASO The Association for Cancer Surgery, and the European Society of Surgical Oncology. All rights reserved.

\section{Introduction}

As a consequence of improvements in oncological treatment strategies of colon cancer (CC) over the last 20 years, 5 -year survival rates have reached $70 \%$ for locally advanced disease [1-3]. Due to implementation of nationwide screening recommendations allowing timely detection and treatment, CC incidence is decreasing in well-resourced Western countries [4,5]. Despite these advances, colorectal cancer still accounted for an estimated 50,630 deaths in the United States in 2018 [6]. Furthermore, with

\footnotetext{
* Corresponding author. Division of Colon and Rectal Surgery, Mayo Clinic, 200 First Street SW, Rochester, MN, 55905, USA.

E-mail address: behm.kevin@mayo.edu (K.T. Behm).

1 Shared first authorship.
}

sedentary lifestyle, obesity and unfavorable dietary patterns are considered potential contributors to explain the rise in CC incidence by $1.6 \%$ per year among adults younger than 50 years was observed [7].

Surgical resection remains the cornerstone treatment for early and locally advanced CC. Known markers of surgical quality include margin status and adequate lymph node harvest, but do not include time from diagnosis to resection [8,9]. From health care policy standpoint, surgical care without significant delay is an important quality metric used by healthcare providers reflecting system capacity and for benchmarking purposes [10,11].

Logically it should follow that prolonged delays to surgery in cancer patients should be associated with disease progression and worse long term outcomes. Studies looking at the impact of delays to surgery are limited and conflicting. Several recent studies have 
not revealed a significant association between a prolonged interval to CC resection and long-term survival [12-15]. However, other large-scale population-based studies showed ambiguous results $[16,17]$. As healthcare models in the United States continue to evolve, access challenges and treatment delays could impact larger groups of patients. Therefore, understanding the consequences of treatment delays on outcomes in patients with CC is essential for appropriate resource allocation and optimization of oncologic outcomes.

This present study aimed to assess the independent impact of delayed time from diagnosis to surgical intervention on overall survival in patients with stage I-III colon cancer.

\section{Material and methods}

\section{Patients and data registry}

A retrospective analysis using the National Cancer database (NCDB) was conducted of all consecutive patients diagnosed between 2004 and 2013 with stage I-III colon cancer who were treated with primary elective (planned admission) surgery with curative (not palliative) intent. Structure, contents and methodology of this nationwide, validated assessment have been previously described; overall, about $70 \%$ of newly diagnosed cancers are reported $[18,19]$. Registry-based data derive from more than 1500 by the Commission of Cancer $(\mathrm{CoC})$ accredited facilities with the aim to track and analyze patients with malignant cancer. Data elements are collected and submitted to the NCDB from CoC-accredited cancer program registries using nationally standardized data item and coding definitions, as specified in the CoC's Facility Oncology Registry Data Standards, and nationally standardized data transmission format specifications coordinated by the North American Association of Central Cancer Registries. To date, 39 million analytic patient cases have been submitted [20]. NCDB data serve two purposes: quality improvement and quality research. In 2011, the Rapid Quality Reporting System (RQRS) was developed and made available to hospitals in the NCDB, aiming to get more timely data from hospital registries to provide performance rates for quality measures. Today RQRS is a required component of participation in the NCDB. The diagnosis date is the recorded date of initial diagnosis by a physician for the tumor being reported (clinically or histologically confirmed). The Mayo Clinic institutional review board approved this study.

Patients were identified by cross-referencing codes C18.0-C18.7 (colon) with histology codes 8140, 8210, 8211, 8220, 8221, 8255, $8260,8261,8262,8263,8480,8481,8490,8510,8560,8571,8574$. Included were all patients with clinical AJCC category T1-T4 and/or N0-N2. Patients with stage IV disease, undergoing any form of neoadjuvant treatment (either chemo-or radiotherapy) or resections yielding positive macroscopic resection margins (R2) were excluded from the analysis. Delay from diagnosis to primary surgery was assessed and patients were further divided in two groups according to treatment delay: Short and long delays were defined as lower and upper quartiles of time from diagnosis to surgery, respectively.

Demographic information included age at surgery, sex, race, comorbidities as assessed by the Charlson-Deyo Score [21], categorized as 0,1 or at least 2, tumor location (left-sided, right-sided or transverse colon), surgical approach (open, laparoscopic or robotic) and socioeconomic factors such as insurance type (private, government or none) and facility type (academic/research or community cancer program). Pathologic features were pathological tumor stage according to AJCC [22], presence of lymphovascular (LVI) and perineural invasion (PNI, reported in NCDB since 2010), histologic subtype (signet-ring/mucinous adenocarcinoma versus adenocarcinoma without signet-ring/mucinous features), tumor differentiation (well, moderate or poor) and surgical margin status (free margins $=\mathrm{R} 0$ versus cancer cells present microscopically at the resection margin $=\mathrm{R} 1$ ). Intra- and postoperative specifics included (index) length of hospital stay after primary surgery, any unplanned readmission within 30 days of surgery and administration of any form of adjuvant chemotherapy.

The primary endpoint was overall survival (OS). All clinicopathological data potentially predictive of survival were included in univariable and multivariable analyses to determine whether treatment delay was independently associated with overall survival after correction for confounding factors.

\section{Statistical analysis}

Qualitative data are presented as numbers with percentages, and quantitative data as median (interquartile range). Clinicopathological characteristics were compared between both groups (short vs. long delay to surgery) using the Kruskal-Wallis test for continuous variables and Pearson's $\chi 2$ test for categorical variables. Unadjusted overall survival was estimated using the Kaplan-Meier method. A log rank test was performed to assess the association of each potential predictive factor with overall survival. A multivariable Cox regression model was used to identify the independent impact of each factor on OS. Backwards selection was used to determine independent predictors of overall survival in the multivariable model. $P<0 \cdot 050$ was considered statistically significant. The functional form of time to treatment was examined using a smoothing spline for the non-adjusted and adjusted outcome of death. Statistical analysis was performed using $S A S \circledR$ version 9.4 (SAS Institute, Cary, North Carolina, USA) and R version 3.4.2 (R Foundation for Statistical Computing, Vienna, Austria).

\section{Results}

In total, 118,504 patients (56,852 male, $48 \%$ ) were included with a median age of 69 (IQR 59-78) years (online appendix 1). Median time from diagnosis to colectomy was 24 days (IQR $16-36$ ). Time to treatment was $<16$ days in the short delay group (31,171 patients, lower quartile) and $\geq 37$ days in the long delay group (29,617 patients, upper quartile). Demographics of both groups are displayed in Table 1. Comorbidities were preponderant in the long delay group, whereas advanced tumor stages were more frequent in the short delay group (both $\mathrm{p}<0.001$ ). Pathologic features of both groups are summarized in Table 2. Patients in the short delay group presented more advanced disease according to overall tumor stage, T-stage, N-stage, PNI and LVI (all p $<0.001$, online appendix 2). Table 3 outlines length of stay during index hospitalization and unplanned readmissions. Neither of these features was significantly different between the two groups. Across all stages, adjuvant chemotherapy was administered in $27.3 \%$ of patients, with a significantly higher rate in the short delay group (33.9 vs. $20.4 \%$, $\mathrm{p}<0.001$ ), going along with advanced tumor stage in this group.

\section{Overall survival}

Median follow-up was 5.3 years. OS was 75.4 vs. $71.9 \%$ at 5 years and 56.6 vs. $49.7 \%$ at 10 years in short and long delay groups, respectively ( $\mathrm{p}<0.0001$, Fig. 1 ).

Multivariable analysis of treatment delay as a continuous variable revealed a significant impact on OS (HR 1.06, 95\% CI 1.05-1.07 per 14 day-delay, Table 4). Further independent risk factors affecting long-term outcome negatively were advanced age, male gender, comorbidities, right-sided and transverse tumors as compared to left-sided location, advanced tumor stage, R1 margin, 
Table 1

Demographic and surgery-related parameter.

\begin{tabular}{|c|c|c|c|c|}
\hline & Long delay $(\mathrm{n}=29617)$ & Short delay $(\mathrm{n}=31171)$ & All patients $(\mathrm{n}=60788)$ & p value \\
\hline Age at Diagnosis (median, IQR) & $70(60-79)$ & $68(57-77)$ & $69(59-78)$ & $<0.0001^{\mathrm{a}}$ \\
\hline Sex (male) (\%) & $14617(49.4)$ & $14750(47.3)$ & $29367(48.3)$ & $<0.0001^{\mathrm{b}}$ \\
\hline Charlson-Deyo Score (\%) & & & & $<0.0001^{\mathrm{b}}$ \\
\hline 0 & $18884(63.8)$ & $22257(71.4)$ & $41141(67.7)$ & \\
\hline 1 & $7504(25.3)$ & $6705(21.5)$ & $14209(23.4)$ & \\
\hline$\geq 2$ & 3229 (10.9) & $2209(7.1)$ & $5438(8.9)$ & \\
\hline Tumor location & & & & $<0.0001^{\mathrm{b}}$ \\
\hline Right-sided & 13008 (43.9) & $14578(46.8)$ & $27586(45.4)$ & \\
\hline Left-sided & $11625(39.3)$ & $10936(35.1)$ & $22588(37.2)$ & \\
\hline Transverse & $4957(16.7)$ & $5657(18.1)$ & $10614(17.5)$ & \\
\hline Surgical Approach & & & & $<0.0001^{\mathrm{b}}$ \\
\hline Robotic & $549(4.4)$ & $336(2.9)$ & $885(3.6)$ & \\
\hline Laparoscopic & $6685(53.3)$ & $5886(50.1)$ & $12571(51.7)$ & \\
\hline Open & $5314(42.3)$ & $5531(47.1)$ & $10845(44.6)$ & \\
\hline Missing & 17069 & 19418 & 36487 & \\
\hline Race & & & & $<0.0001^{\mathrm{b}}$ \\
\hline White & $23835(80.5)$ & $26989(86.6)$ & $50842(83.6)$ & \\
\hline Black & $4366(14.7)$ & $2795(9)$ & $7161(11.8)$ & \\
\hline Other & $1127(3.8)$ & $1113(3.6)$ & $2240(3.7)$ & \\
\hline Unknown & $289(1)$ & $274(0.9)$ & $563(0.9)$ & \\
\hline Insurance type & & & & $<0.0001^{\mathrm{b}}$ \\
\hline No insurance & $661(2.2)$ & $647(2.1)$ & $1308(2.2)$ & \\
\hline Private & $9800(33.1)$ & 12377 (39.7) & $22177(36.5)$ & \\
\hline Government & $18832(63.6)$ & $17825(57.2)$ & $36657(60.3)$ & \\
\hline Unknown & $324(1.1)$ & $322(1)$ & $646(1.1)$ & \\
\hline Facility type & & & & $<0.0001^{\mathrm{b}}$ \\
\hline Academic/Research & $10213(34.5)$ & $6951(22.3)$ & $17164(28.2)$ & \\
\hline Community Cancer Program & $15665(52.9)$ & $20308(55.1)$ & $35973(59.2)$ & \\
\hline Other & $3739(12.6)$ & $3912(12.6)$ & $7651(12.6)$ & \\
\hline
\end{tabular}

signet-ring and mucinous histological subtypes and omission of adjuvant chemotherapy.

As shown in Fig. 2, the unadjusted and adjusted hazard ratio for death was consistent among delays of less than 30 days, but increased continuously with delay times of longer than 30 days, to become significant after a delay of 40 days (lower $95 \%$ confidence interval of spline curve crosses 1 ). An arbitrary cutoff of 3 months was associated with an approximately 1.4 times higher mortality.

\section{Discussion}

Using a validated national cancer registry, our study revealed a statistically significant negative impact on overall survival when treatment was delayed beyond 40 days after diagnosis in patients with non-metastatic colon cancer. A treatment delay of 3 months was associated with a 1.4 times higher mortality. This analysis, which was adjusted for demographic, socioeconomic, pathologic and oncological treatment-related confounders, provides evidence to support surgical resection of $\mathrm{CC}$ within 40 days of diagnosis. This may be a relevant observation, since potential long-term sequelae of delayed surgical management after CC diagnosis may have been perceived less important in the light of ever-rising healthcare expenses focusing on short-term quality metrics [23,24].

From a methodological point of view, a 3-step approach was chosen to answer the clinically relevant question of a potential detrimental impact of delayed curative surgery of newly diagnosed colon cancer. First, upper (long delay) and lower (short delay) quartiles of the study cohort were compared and revealed significant differences (Fig. 1). Second, the independent impact of treatment delay was confirmed through multivariable analysis, considering a list of relevant potential confounders (Table 4). Finally, this study aimed to define a pragmatic therapeutic window to provide guidance to treating clinicians.
Comparing our data to the current literature reveals methodological differences but also conflicting results. In a recent singlecenter study on 769 patients, the authors divided treatment delays to surgery into quartiles, similarly as this present study [15]. Interestingly, an inverse relation between delay and death was found through all stages but stage IV patients. However, this counter-intuitive association became largely insignificant after multivariable analysis. While the authors explained this finding by appropriate case prioritization, they concluded that treatment delay does not lead to any worsening of prognosis. Wanis et al. [13] reported on 908 patients with stage I to III colon cancer by stratifying treatment delay into 30-day intervals. In their study, even delays of 2-3 months did not adversely impact on overall survival and were considered too short to result in clinically significant tumor progression. However, the authors acknowledged limitations of their study to provide adequate sample sized subgroup analyses examining longer treatment delays, a shortcoming that may be addressed by this present analysis. Similarly to these aforementioned studies, the introduction of the 62-day rule from referral to treatment in the United Kingdom (2-week rule from symptoms to diagnosis) has not translated in improved survival [25]. A population-based Korean large-scale study revealed compromised oncological outcome only when surgical treatment of CC was delayed in low-to medium-volume hospitals [17]. The authors emphasized the critical role of centralization in order to achieve better outcomes. A population-based Danish study revealed a therapeutic delay of at least 60 days as a negative prognostic factor for long-term survival from rectal but not colon cancer [16], however by looking at provider delay and hospital delay together across all tumor stages. Finally, a recent systematic review of 5 observational studies including 13,514 patients revealed no association between treatment delay and reduced overall survival [26]. However, according to the authors, the validity of the 
Table 2

Pathological features.

\begin{tabular}{|c|c|c|c|c|}
\hline & Long delay $(\mathrm{n}=29617)$ & Short delay $(\mathrm{n}=31171)$ & All patients $(\mathrm{n}=60788)$ & p value \\
\hline Pathologic Stage & & & & $<0.0001$ \\
\hline 0 & $1130(3.8 \%)$ & $356(1.1 \%)$ & $1486(2.4 \%)$ & \\
\hline 1 & $11888(40.2 \%)$ & $8011(25.8 \%)$ & $19899(32.8 \%)$ & \\
\hline 2 & $8866(29.9 \%)$ & $11939(38.4 \%)$ & $20805(34.2 \%)$ & \\
\hline 3 & $7700(26.1 \%)$ & $10812(34.7 \%)$ & $18512(30.6 \%)$ & \\
\hline Pathologic T Stage & & & & $<0.0001$ \\
\hline 0 & $1148(3.9 \%)$ & $363(1.2 \%)$ & $1511(2.5 \%)$ & \\
\hline 1 & $7719(26.1 \%)$ & $3448(11.1 \%)$ & $11167(18.4 \%)$ & \\
\hline 2 & $5866(19.8 \%)$ & $6037(19.4 \%)$ & $11903(19.6 \%)$ & \\
\hline 3 & $13353(45.1 \%)$ & $18988(60.9 \%)$ & $32341(53.2 \%)$ & \\
\hline 4 & $1531(5.2 \%)$ & $2335(7.5 \%)$ & $3866(6.4 \%)$ & \\
\hline Pathologic N Stage & & & & $<0.0001$ \\
\hline 0 & $21894(73.9 \%)$ & $20316(65.2 \%)$ & $42210(69.4 \%)$ & \\
\hline 1 & $5501(18.6 \%)$ & $7149(22.9 \%)$ & $12650(20.8 \%)$ & \\
\hline 2 & $2222(7.5 \%)$ & $3706(11.9 \%)$ & $5928(9.8 \%)$ & \\
\hline Perineural Invasion & & & & $<0.0001$ \\
\hline Missing & 18192 & 20210 & 38402 & \\
\hline No & $10654(93.3 \%)$ & $10058(91.8 \%)$ & $20712(92.5 \%)$ & \\
\hline Yes & $771(6.7 \%)$ & $903(8.2 \%)$ & $1674(7.5 \%)$ & \\
\hline Lymphovascular Invasion & & & & $<0.0001$ \\
\hline Missing & 18378 & 20303 & 38681 & \\
\hline No & $8965(79.8 \%)$ & $8170(75.2 \%)$ & $17135(77.5 \%)$ & \\
\hline Yes & $2274(20.2 \%)$ & $2698(24.8 \%)$ & $4972(22.5 \%)$ & \\
\hline Histology & & & & 0.0081 \\
\hline Signet-ring/Mucinous & $2849(9.6 \%)$ & $3199(10.3 \%)$ & $6048(9.9 \%)$ & \\
\hline Non-signet-ring/non-mucinous & $26768(90.4 \%)$ & $27972(89.7 \%)$ & $54740(90.1 \%)$ & \\
\hline Grade/Differentiation & & & & $<0.0001$ \\
\hline Well & $3480(11.8 \%)$ & $2919(9.4 \%)$ & $6399(10.5 \%)$ & \\
\hline Moderately & $19877(67.1 \%)$ & $21582(69.2 \%)$ & $41459(68.2 \%)$ & \\
\hline Poorly or none & $4127(13.9 \%)$ & $5788(18.6 \%)$ & $9915(16.3 \%)$ & \\
\hline Unknown & $2133(7.2 \%)$ & $882(2.8 \%)$ & $3015(5.0 \%)$ & \\
\hline Surgical Margins & & & & $<0.0001$ \\
\hline RO & $29255(98.8 \%)$ & 30594 (98.1\%) & $59849(98.5 \%)$ & \\
\hline $\mathrm{R} 1$ & $362(1.2 \%)$ & $577(1.9 \%)$ & $939(1.5 \%)$ & \\
\hline
\end{tabular}

Chi-Square.

Pathologic features of patients with short delay to surgery ( $<16$ days, $\mathrm{n}=32031$ ) and patients with long delay to surgery ( $>37$ days, $\mathrm{n}=33517$ ).

Table 3

Timing of index surgery and postoperative outcome/treatments.

\begin{tabular}{|c|c|c|c|c|}
\hline & Long delay $(\mathrm{n}=29617)$ & Short delay $(\mathrm{n}=31171)$ & All patients $(\mathrm{n}=60788)$ & $\mathrm{p}$ value \\
\hline \multicolumn{4}{|c|}{ Time from diagnosis to first treatment (days) } & $<0.0001^{\mathrm{a}}$ \\
\hline median, IQR & $50(42-66)$ & $13(11-15)$ & $16(13-49)$ & \\
\hline mean $\pm \mathrm{SD}$ & $60.9 \pm 32.9$ & $12.7 \pm 2.2$ & $36.2 \pm 33.3$ & \\
\hline \multicolumn{5}{|c|}{ Index length of hospital stay (days) } \\
\hline (median, IQR) & $5(4-7)$ & $5(4-7)$ & $5(4-7)$ & $0.2934^{\mathrm{a}}$ \\
\hline \multicolumn{4}{|c|}{ Unplanned Readmission } & $0.8843^{\mathrm{b}}$ \\
\hline No & $27650(95.1 \%)$ & $29209(95.1 \%)$ & $56859(95.1 \%)$ & \\
\hline Yes & $1424(4.9 \%)$ & $1496(4.9 \%)$ & $2920(4.9 \%)$ & \\
\hline Missing & 543 & 466 & 1009 & \\
\hline \multicolumn{4}{|c|}{ Adjuvant Chemotherapy } & $<0.0001^{\mathrm{b}}$ \\
\hline No & $23563(79.6 \%)$ & $20604(66.1 \%)$ & $44167(72.7 \%)$ & \\
\hline Yes & $6054(20.4 \%)$ & 10567 (33.9\%) & $16621(27.3 \%)$ & \\
\hline
\end{tabular}

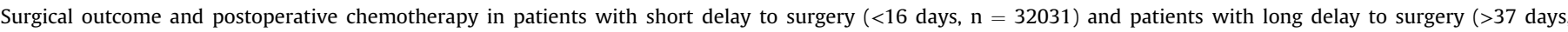
$\mathrm{n}=33517$ ).

a Kruskal Wallis.

b Chi-Square.

results was limited by the heterogeneity of included studies regarding the specific time period of the delay and the reported outcomes. The observations of the aforementioned different studies are challenged by the results of this present analysis, with the rather linear pattern of over-mortality beyond the 40-day interval supporting best-possible adherence to the suggested therapeutic window.

Interestingly, patients in the long delay group in our study had more comorbid conditions as assessed by the validated CharlsonDeyo score, which may reflect the need for either further medical workup or preconditioning in these patients. On the other hand, advanced tumor stage was preponderant in the short delay group, which may reflect a higher degree of concern leading to earlier surgical intervention. Since OS was adjusted for both confounders, this study does not provide a reliable explanation for the associative findings of delay and mortality. Potential explanations may be related to tumor biology (i.e. unidentified systemic metastases by the time of tumor staging) or behavioral aspects with subsequent selection bias (i.e. less compliance to follow-up treatments of the delayed treatment group). With this respect, the findings should 


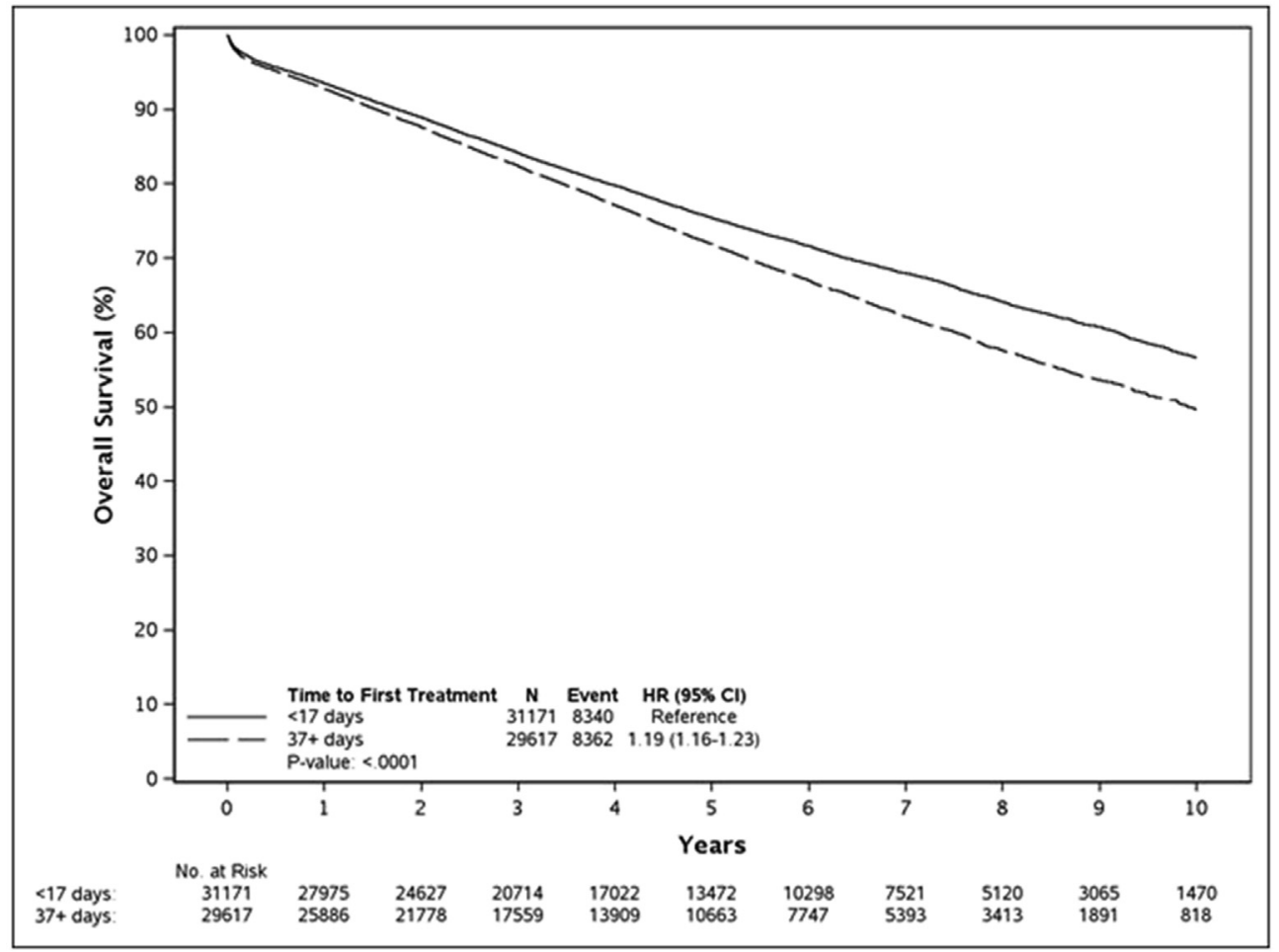

\begin{tabular}{|c|c|c|}
\hline & $\begin{array}{c}\text { Median } \\
(95 \% \mathrm{CI})^{1}\end{array}$ & $\begin{array}{l}\text { Survival Estimates } \\
\qquad(95 \% \mathrm{CI})^{1}\end{array}$ \\
\hline \multicolumn{3}{|c|}{ Time to First Treatment } \\
\hline$<17$ days & $11.4(11.1-11.5)$ & $\begin{array}{ll}1 \text { year: } & 93.5(93.2-93.8 \%) \\
5 \text { years: } & 75.4(74.9-76.0 \%) \\
10 \text { years: } 56.6(55.6-57.6 \%)\end{array}$ \\
\hline $37+$ days & $9.9(9.7-10.2)$ & $\begin{array}{l}1 \text { year: } \quad 92.8(92.5-93.1 \%) \\
5 \text { years: } 71.9(71.3-72.5 \%) \\
10 \text { years: } 49.7(48.5-50.9 \%)\end{array}$ \\
\hline
\end{tabular}

${ }^{1}$ Kaplan-Meier method

Fig. 1. Overall survival.

Survival analysis comparing patients with short delay to surgery $(\mathrm{n}=32031)$ and patients with long delay to surgery ( $\mathrm{n}=33517)$. 
Table 4

Cox regression analysis.

\begin{tabular}{|c|c|c|c|c|}
\hline & \multicolumn{2}{|l|}{ Univariate analysis } & \multicolumn{2}{|c|}{ Multivariable analysis } \\
\hline & $\mathrm{HR}(95 \% \mathrm{CI})$ & $\mathrm{P}$ & $\operatorname{HR}(95 \% \mathrm{CI})$ & $\mathrm{P}$ \\
\hline Days between diagnosis and surgery (per 14 days, 140 day cap) & $1.08(1.07-1.09)$ & $<0.001$ & $1.06(1.05-1.07)$ & $<0.001$ \\
\hline Age (per 10 years) & $1.81(1.79-1.83)$ & $<0.001$ & $1.68(1.65-1.7)$ & $<0.001$ \\
\hline Male gender & $1.09(1.06-1.11)$ & $<0.001$ & $1.29(1.26-1.32)$ & $<0.001$ \\
\hline Charlson-Deyo Score & & $<0.001$ & & $<0.001$ \\
\hline 0 & 1 (reference) & & 1 (reference) & \\
\hline $1-2$ & $1.89(1.85-1.93)$ & & $1.57(1.53-1.61)$ & \\
\hline Tumor location & & $<0.001$ & & $<0.001$ \\
\hline Left-sided & 1 (reference) & & 1 (reference) & \\
\hline Right-sided & $1.44(1.4-1.48)$ & & $1.03(1-1.06)$ & \\
\hline Transverse & $1.38(1.34-1.43)$ & & $1.07(1.04-1.11)$ & \\
\hline Pathologic T stage & & $<0.001$ & & $<0.001$ \\
\hline 0 & 1 (reference) & & 1 (reference) & \\
\hline 1 & $1.07(0.97-1.18)$ & & $1.03(0.93-1.15)$ & \\
\hline 2 & $1.61(1.46-1.78)$ & & $1.31(1.18-1.45)$ & \\
\hline 3 & $2.24(2.04-2.46)$ & & $1.71(1.55-1.9)$ & \\
\hline 4 & $4.14(3.74-4.59)$ & & $3.01(2.69-3.36)$ & \\
\hline Pathologic N stage & & $<0.001$ & & $<0.001$ \\
\hline 0 & 1 (reference) & & 1 (reference) & \\
\hline 1 & $1.34(1.3-1.37)$ & & $1.82(1.76-1.88)$ & \\
\hline 2 & $2.34(2.27-2.41)$ & & $3.31(3.19-3.44)$ & \\
\hline Adjuvant chemotherapy & & $<0.001$ & & $<0.001$ \\
\hline No & 1 (reference) & & 1 (reference) & \\
\hline Yes & $0.8(0.78-0.82)$ & & $0.55(0.54-0.57)$ & \\
\hline Histology & & $<0.001$ & & $<0.001$ \\
\hline Non-signet-ring/non-mucinous & 1 (reference) & & 1 (reference) & \\
\hline Signet-ring/mucinous & $1.38(1.33-1.42)$ & & $1.07(1.04-1.11)$ & \\
\hline Surgical margins & & $<0.001$ & & $<0.001$ \\
\hline RO & 1 (reference) & & 1 (reference) & \\
\hline $\mathrm{R} 1$ & $2.46(2.31-2.36)$ & & $1.57(1.47-1.68)$ & \\
\hline
\end{tabular}

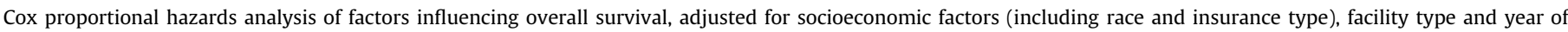
diagnosis (2004-2013).

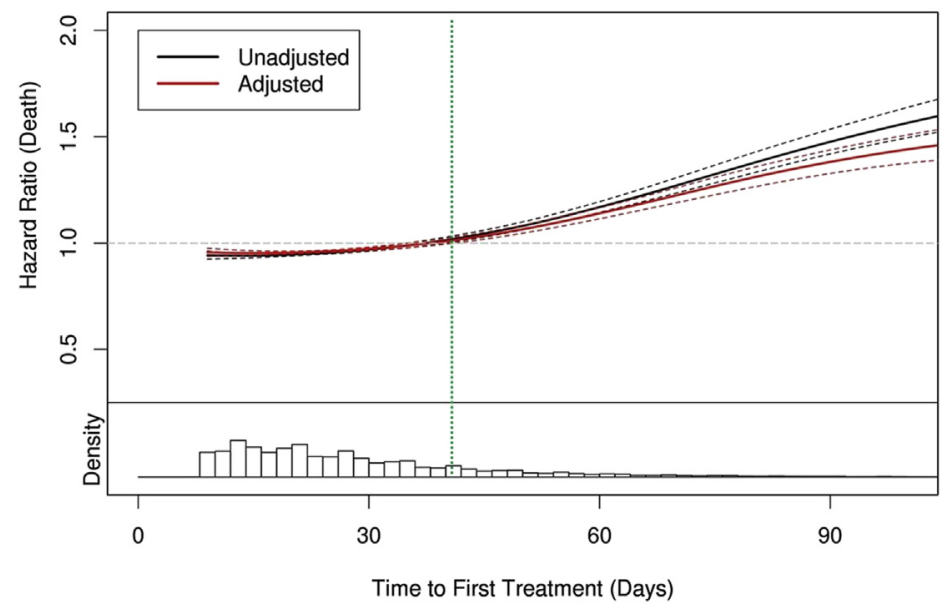

Fig. 2. Mortality according to time to surgery.

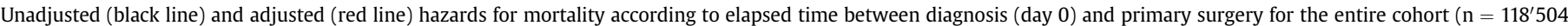
patients). Dashed lines represent $95 \%$ confidence intervals. The green dashed line represents the cut-off at 40 days when the lower $\mathrm{CI}$ of the spline curve crosses 1.

not be interpreted as prescriptive or dogmatic, but rather encourage further research through adequately powered studies that investigate causative explanations.

The present study has limitations that need to be addressed. The analysis included both academic institutions and rural community hospitals, but further stratification according to hospital volume was not possible. One of the shortcomings of the NCDB dataset is the lack of assessment of disease-specific survival. Thus, it is unclear how OS is impacted by other factors besides malignancy and has thus, in the absence of causality, to be considered a surrogate marker. Furthermore, NCDB does not track onset of symptoms, which would arguably be of value to assess the impact of prolonged waiting time further, even though the large sample size may help to alleviate this bias. Postoperative complications have been assessed through surrogates length of stay and readmissions, whereas specific morbidity was not available. Furthermore, specifics on postoperative oncological treatment were not available. Despite these limitations, the large sample size and the uniform number of 
patients in both groups through stratification by quartiles limit the risk of bias.

\section{Conclusions}

The results of this study using a national database suggest a potential oncologic benefit to patients undergoing surgery for colon cancer within 40 days of diagnosis. Causative explanations for these findings need to be further investigated.

\section{Declaration of competing interest}

None.

\section{Appendix A. Supplementary data}

Supplementary data to this article can be found online at https://doi.org/10.1016/j.ejso.2019.11.513.

\section{References}

[1] van Steenbergen LN, Elferink MA, Krijnen P, Lemmens VE, Siesling S Rutten HJ, et al. Improved survival of colon cancer due to improved treatment and detection: a nationwide population-based study in The Netherlands 1989-2006. Ann Oncol 2010;21(11):2206-12. https://doi.org/10.1093/ annonc/mdq227.

[2] van den Broek CB, Bastiaannet E, Dekker JW, Portielje JE, de Craen AJ, Elferink MA, et al. Time trends in chemotherapy (administration and costs) and relative survival in stage III colon cancer patients - a large populationbased study from 1990 to 2008. Acta Oncol 2013;52(5):941-9. https:/ doi.org/10.3109/0284186X.2012.739730.

[3] Miller KD, Siegel RL, Lin CC, Mariotto AB, Kramer JL, Rowland JH, et al. Cancer treatment and survivorship statistics, 2016. CA A Cancer J Clin 2016;66(4): 271-89. https://doi.org/10.3322/caac.21349.

[4] Knudsen AB, Zauber AG, Rutter CM, Naber SK, Doria-Rose VP, Pabiniak C, et al Estimation of benefits, burden, and harms of colorectal cancer screening strategies: modeling study for the US preventive services task force. J Am Med Assoc 2016;315(23):2595-609. https://doi.org/10.1001/jama.2016.6828.

[5] Edwards BK, Ward E, Kohler BA, Eheman C, Zauber AG, Anderson RN, et al. Annual report to the nation on the status of cancer, 1975-2006, featuring colorectal cancer trends and impact of interventions (risk factors, screening and treatment) to reduce future rates. Cancer 2010;116(3):544-73. https:/ doi.org/10.1002/cncr.24760.

[6] Siegel RL, Miller KD, Jemal A. Cancer statistics, 2018. CA A Cancer J Clin 2018;68(1):7-30. https://doi.org/10.3322/caac.21442.

[7] Siegel RL, Jemal A, Ward EM. Increase in incidence of colorectal cancer among young men and women in the United States. Cancer Epidemiol Biomark Prev 2009;18(6):1695-8. https://doi.org/10.1158/1055-9965.EPI-09-0186.

[8] Chen SL, Steele SR, Eberhardt J, Zhu K, Bilchik A, Stojadinovic A. Lymph node ratio as a quality and prognostic indicator in stage III colon cancer. Ann Surg 2011;253(1):82-7. https://doi.org/10.1097/SLA.0b013e3181ffa780.

[9] Shulman LN, Browner AE, Palis BE, Mallin K, Kakade S, Carp N, et al. Compliance with cancer quality measures over time and their association with survival outcomes: the commission on cancer's experience with the quality measure requiring at least 12 regional lymph nodes to be removed and analyzed with colon cancer resections. Ann Surg Oncol 2019. https://doi.org/ 10.1245/s10434-019-07323-w.

[10] Rutqvist LE. Waiting times for cancer patients-a "slippery slope" in oncology. Acta Oncol 2006;45(2):121-3. https://doi.org/10.1080/02841860600549204.

[11] Brenkman HJF, Visser E, van Rossum PSN, Siesling S, van Hillegersberg R, Ruurda JP. Association between waiting time from diagnosis to treatment and survival in patients with curable gastric cancer: a population-based study in The Netherlands. Ann Surg Oncol 2017;24(7):1761-9. https://doi.org/ 10.1245/s10434-017-5820-8.

[12] Roland CL, Schwarz RE, Tong L, Ahn C, Balch GC, Yopp AC, et al. Is timing to delivery of treatment a reliable measure of quality of care for patients with colorectal adenocarcinoma? Surgery 2013;154(3):421-8. https://doi.org/ 10.1016/j.surg.2013.04.049.

[13] Wanis KN, Patel SVB, Brackstone M. Do moderate surgical treatment delays influence survival in colon cancer? Dis Colon Rectum 2017;60(12):1241-9. https://doi.org/10.1097/DCR.0000000000000857.

[14] Flemming JA, Nanji S, Wei X, Webber C, Groome P, Booth CM. Association between the time to surgery and survival among patients with colon cancer: a population-based study. Eur J Surg Oncol 2017;43(8):1447-55. https:// doi.org/10.1016/j.ejso.2017.04.014.

[15] Amri R, Bordeianou LG, Sylla P, Berger DL. Treatment delay in surgicallytreated colon cancer: does it affect outcomes? Ann Surg Oncol 2014;21(12): 3909-16. https://doi.org/10.1245/s10434-014-3800-9.

[16] Iversen LH, Antonsen S, Laurberg S, Lautrup MD. Therapeutic delay reduces survival of rectal cancer but not of colonic cancer. Br J Surg 2009;96(10): 1183-9. https://doi.org/10.1002/bjs.6700.

[17] Yun YH, Kim YA, Min YH, Park S, Won YJ, Kim DY, et al. The influence of hospital volume and surgical treatment delay on long-term survival after cancer surgery. Ann Oncol 2012;23(10):2731-7. https://doi.org/10.1093/ annonc/mds101.

[18] Raval MV, Bilimoria KY, Stewart AK, Bentrem DJ, Ko CY. Using the NCDB for cancer care improvement: an introduction to available quality assessment tools. J Surg Oncol 2009;99(8):488-90. https://doi.org/10.1002/jso.21173.

[19] Merkow RP, Rademaker AW, Bilimoria KY. Practical guide to surgical data sets: national cancer database (NCDB). JAMA Surg 2018;153(9):850-1. https://doi.org/10.1001/jamasurg.2018.0492.

[20] McCabe RM. National cancer database: the past, present, and future of the cancer registry and its efforts to improve the quality of cancer care. Semin Radiat Oncol 2019;29(4):323-5. https://doi.org/10.1016/ j.semradonc.2019.05.005.

[21] Deyo RA, Cherkin DC, Ciol MA Adapting a clinical comorbidity index for use with ICD-9-CM administrative databases. J Clin Epidemiol 1992;45(6):613-9.

[22] Edge SB, Compton CC. The American Joint Committee on Cancer: the 7th edition of the AJCC cancer staging manual and the future of TNM. Ann Surg Oncol 2010;17(6):1471-4. https://doi.org/10.1245/s10434-010-0985-4.

[23] Greer NL, Gunnar WP, Dahm P, Lee AE, MacDonald R, Shaukat A, et al. Enhanced recovery protocols for adults undergoing colorectal surgery: a systematic review and meta-analysis. Dis Colon Rectum 2018;61(9):1108-18. https://doi.org/10.1097/DCR.0000000000001160.

[24] Vlug MS, Wind J, Hollmann MW, Ubbink DT, Cense HA, Engel AF, et al. Laparoscopy in combination with fast track multimodal management is the best perioperative strategy in patients undergoing colonic surgery: a randomized clinical trial (LAFA-study). Ann Surg 2011;254(6):868-75. https://doi.org/ 10.1097/SLA.0b013e31821fd1ce.

[25] Zafar A, Mak T, Whinnie S, Chapman MA. The 2-week wait referral system does not improve 5-year colorectal cancer survival. Colorectal Dis 2012;14(4): e177-80. https://doi.org/10.1111/j.1463-1318.2011.02826.x.

[26] Hangaard Hansen C, Gogenur M, Tvilling Madsen M, Gogenur I. The effect of time from diagnosis to surgery on oncological outcomes in patients undergoing surgery for colon cancer: a systematic review. Eur J Surg Oncol 2018;44(10):1479-85. https://doi.org/10.1016/j.ejso.2018.06.015. 